



\section{Quality-Controlled Logistics with Internet of Things: A conceptual framework}

Authors: dr. X. (Xuezhen) Guo, drs.ing. J.C.M.A. (Joost) Snels and ir. S. (Seth) Tromp MTD BA

This study was carried out by Wageningen Food \& Biobased Research, subsidised and commissioned by the Dutch Ministry of Agriculture, Nature and Food Quality and funded by NWO. 
WFBR Project number: 6230188100

Version: Final

Reviewer: dr. R.B. (Bob) Castelein

Approved by: dr.ir. H. (Henk) Wensink

Subsidized by: the Dutch Ministry of Agriculture, Nature and Food Quality

Funded by: NWO

Commissioned by: the Dutch Ministry of Agriculture, Nature and Food Quality

Confidentiality of the report: Public

This publication is part of the project Quality Controlled Logistics in IoT-enabled Perishable Supply

Chains (439.19.609) of the research programme Accelerator - Kennis en innovatie voor een

concurrerende logistieke sector which is (partly) financed by the Dutch Research Council (NWO)

The research that is documented in this report was conducted in an objective way by researchers who act impartial with respect to the client(s) and sponsor(s). This report can be downloaded for free at https://doi.org/10.18174/541694 or at www.wur.eu/wfbr (under publications).

(C) 2021 Wageningen Food \& Biobased Research, institute within the legal entity Stichting Wageningen Research.

The client is entitled to disclose this report in full and make it available to third parties for review. Without prior written consent from Wageningen Food \& Biobased Research, it is not permitted to:

a. use this report for the purposes of making claims, conducting legal procedures, for (negative) publicity, and for recruitment in a more general sense;

b. use the name of Wageningen Food \& Biobased Research in a different sense than as the author of this report.

PO box 17, 6700 AA Wageningen, The Netherlands, T + 31 (0)317 4800 84, E info.wfbr@wur.nl, www.wur.eu/wfbr.

All rights reserved. No part of this publication may be reproduced, stored in a retrieval system of any nature, or transmitted, in any form or by any means, electronic, mechanical, photocopying, recording or otherwise, without the prior permission of the publisher. The publisher does not accept any liability for inaccuracies in this report. 


\section{Contents}

$\begin{array}{ll}\text { Summary } & 4\end{array}$

1 Introduction $\quad 5$

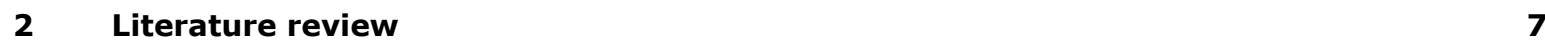

$\begin{array}{lll}2.1 & \text { Sensor application in quality-controlled logistics } & 7\end{array}$

2.2 Quality-decay modeling $\quad 8$

$\begin{array}{ll}2.3 \text { Knowledge gap } & 9\end{array}$

3 Method $r$

4 Conceptual framework $r 12$

$\begin{array}{llr}4.1 & \text { Logistic operations } & 12\end{array}$

4.1.1 Three-level selections $\quad 12$

4.1.2 Cost-benefit analysis 14

4.1.3 Implementation scheme $\quad 14$

4.2 Distribution network design 16

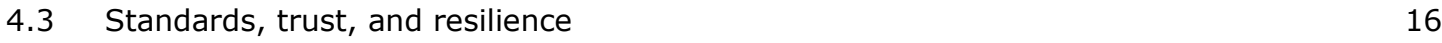

$\begin{array}{llr}5 & \text { Discussion } & 18\end{array}$

$\begin{array}{lr}\text { Literature } & 19\end{array}$ 


\section{Summary}

Food supply is a big challenge that our global society faces, and supply chain innovations are expected to contribute to a more secure, efficient and sustainable food supply. One of the promising innovations is to apply Internet of Things (IoT) to create the so-called data-driven food supply chain with qualitycontrolled logistics. To investigate the feasibility of such innovation, TNO and Wageningen Food \& Biobased Research (WFBR) jointly developed a project ${ }^{1}$ within the NWO Dinalog financing framework to study IoT applications in the Fruits and Vegetable supply chains. The project includes 6 work packages:

- WP1 IoT enabled Quality Controlled Logistics (QCL), including a conceptual framework on IoT enabled QCL, the state-of-the-art supporting technologies, and the SWOT analysis of this QCLconcept.

- WP2 Business analysis, including the use cases for demonstration, the business case analysis and the business model analysis.

- $\quad$ WP3 Design and Solution Development, including the development work needed to demonstrate a proof of concept in a real-life setting.

- WP4 Demonstrations, covering a demonstration of the use cases in a maritime and a continental road trade lane.

- WP5 Evaluation and valorization, make sure that the project knowledge is being disseminated among the target audience and support a broader valorization of the project insights.

- $\quad$ WP6 Project Management, assuring an overall efficient execution of the project and organize and facilitate the cooperation between the consortium parties.

Falling in WP1, this research develops a conceptual framework following a well-accepted conceptual framework development method to analyze the application of quality sensors in the fruit and vegetable supply chain. This framework analyzes added values for sensor applications at the level of logistic operations and the level of strategic distribution network design. A generic procedure was proposed to guide the analysis of the quality-controlled logistic operations in daily business practice. The added values of the accumulated sensor data for quality-controlled network design were also discussed. Other relevant issues including standard establishment, trust enhancement, and resilience improvement in the fruit and vegetable chains were also addressed.

\footnotetext{
${ }^{1}$ Quality Controlled Logistics in IoT-enabled Perishable Supply Chains
} 


\section{Introduction}

Internet of Things (IoT) is expected to be one of the most exciting technological developments in the 21st century. By combining technologies including radio frequency identification (RFID), infrared sensors, global positioning systems, laser scanners, and other information sensing devices, IoT enables any object to be connected to the internet for information exchange and communication, to achieve intelligently identifying, locating, tracking, monitoring and managing a network this object belongs to (Sun, 2012).

IoT and logistics are intrinsically interrelated. Logistics concerns the management of the flow of goods and services, work-in-process inventory, and finished goods from point of origin to point of consumption. From a historical point of view, the origin of IoT can be traced back to the efforts by professors David Brock and Sanjay Sarma in establishing the Auto-ID Centre at the Massachusetts Institute of Technology (MIT). They researched the possibility of putting low-cost RFID tags on all products to track them through the supply chains, which can significantly change the traditional business model. With this new technology, a manufacturer could automatically let a business partner know when a shipment was leaving the dock at a manufacturing facility or warehouse, and a retailer could let the manufacturer know when the goods arrived without the need for human intervention (Minerva et al., 2015). The potential of IoT application in logistics is highly regarded. It can help improve logistics efficiency through multiple stages of supply chains. There are two ways that IoT can influence supply chain management. The basic way is to focus on data processing only, while the advanced way is to perform complex pro-active behaviors based on data processing (Hribernik et al., 2010). Even in the basic way, IoT could already bring in huge benefits at different levels. At the strategic level, it can provide much better supply-chain visibility and traceability in a real-time manner, which allows us to make on-time and effective decisions on supply chain coordination to gain strategic advantages (e.g. chain-level coordinated inventory management). At the operational level, real-time and transparent supply chain data provide ample opportunities for logistics practitioners to improve efficiencies and effectiveness and thus reduce costs. For example, it can increase the productivity of warehouse workers by minimizing their manual workloads (e.g., manual barcode scanning, paperwork, stock-keeping unit (SKU) counting). It can facilitate continuous monitoring of the capacities and throughputs of a warehouse and maximize its utilization. With the help of IoT in real-time stock-position monitoring, store managers will suffer much less overcapacity or stock-out issues because the product allocation team can, based on the on-time inventory information, replenish only the appropriate products to avoid overloading slow-moving SKUs to the stores. . Implementing IoT also enables port managers to mitigate traffic pressure by maximizing utilization and minimize the idle time of every link in its system (Lacey et al., 2015).

Based on the promising prospects, IoT was expected to bring benefits to logistics (or supply chain management in a broader sense) within a short timeframe of 2 to 10 years (Wong et al., 2002). However, the realization of that is far behind its schedule. Nowadays, most companies are still managing their supply chains with traditional IT methods, which rely heavily on manual operations. This may be due to the overestimation of the speed of IT development. The high-speed $5 \mathrm{G}$ internet has not yet been mature for large-scale applications even by today. As a result, the quality of the recorded supply chain data is often not good enough to support high-quality managerial decisions. Moreover, the lead-time for storing, communicating, updating, and reporting the data is usually so long that it leaves no time for decision-makers to take on-time actions. Logistics service providers, such as DHL and UPS showed in the past that they are more willing to embrace IoT technologies and they are also way ahead of companies from other sectors; however, even for them, IoT has been mainly implemented as the track-and-trace application (Lacey et al., 2015), which represents only a small piece of the IoT potential. Given the current situation, it is essential to identify the barriers to IoT application, explore the areas where IoT can add value, and develop theory and good practices to facilitate IoT development in different sectors.

The food industry, especially for the fruits and vegetables (F\&V) sector, is one understudied area in which IoT has great potential to make changes in so-called quality-controlled logistics. F\&V is a sector 
of economic significance. The whole sector was worth 1,249.8 billion US dollars (Fresh Plaza) and accounted for $1.5 \%$ of the global GDP in 2018 (World Bank). Furthermore, since F\&V are highly perishable products, their losses and waste along the supply chains are enormous. Around $50 \%$ of the total food losses and waste (in tons) were attributed to F\&V globally in 2013 which primarily occurred in the postharvest stages (Guo et al., 2019). Therefore, reducing F\&V losses and waste in the postharvest chains are of high importance. IoT, more specifically quality-controlled logistics, which covers quality-sensor technology combined with quality decay models (de Keizer et al., 2017; Jedermann et al., 2014; Van Der Vorst et al., 2009), provides a powerful enabler for the F\&V chain practitioners to improve efficiency and effectiveness, prevent losses and waste, and thus reduce costs. In this research, we analyzed the values that quality-controlled logistics, which covers quality-sensor technology combined with quality decay models, can potentially add to reducing losses and waste at the postharvest stages of F\&V supply chains. A conceptual framework that addresses where and how to apply this technology from a cost-benefit perspective was developed to facilitate the analysis.

In the next section, a comprehensive literature review was conducted to identify the knowledge gap in this area. 
Instead of performing a review of general IoT technologies, the focus of the literature review is on the interface area of the quality-sensor technology and quality decay models applied in quality-controlled logistics. The aim of the literature review is also not to provide an exhausting list of all research in the referred area but to identify the knowledge gap by analyzing the most relevant studies.

Consumers' expectations for good-quality products with a decent shelf life drive the development of the so-called quality-controlled logistics (Smith and Sparks, 2004; Van Der Vorst et al., 2009; van der Vorst et al., 2005; van der Vorst et al., 2007). Quality-controlled logistics is built upon the assumption that product quality at each stage of the supply chain is changing but predictable, goods flows can thereby be proactively controlled and better chain setups can be designed to ensure higher product availability and quality with fewer product losses (van der Vorst et al., 2011). It addresses the dynamic planning, implementing, and controlling of the efficient, effective flow and storage of food products, services, and related information between the point of origin and the point of consumption to meet customers' requirements (van der Vorst et al., 2007). In the context of IoT application, quality-controlled logistics can be referred to as advanced logistics decision making taking into account real-time information on product quality with the help of sensors, data, communication, and other relevant technologies (van der Vorst et al., 2011; Verdouw et al., 2013). The two key components emphasized by this new approach include quality sensors (hardware) and quality-decay models (software) which will be separately addressed in the following two subsections.

\subsection{Sensor application in quality-controlled logistics}

Ben-Daya et al. (2019) did the most recent and comprehensive study on IoT applications in supply chain management. We took their work as the backbone reference to conduct our literature review in this sub-section.

Since the final quality and shelf life of the F\&V products are heavily affected by their temperature conditions, the most commonly applied sensor technology in this area aims at measuring the temperature history of the products. Time Temperature Integrators or Indicators (TTI) are a type of temperature sensors which are considered as a cost-effective tool to monitor the temperature conditions of the food products in the supply chains (Taoukis and Labuza, 2003). Giannakourou and Taoukis (2003) conducted a study to investigate the applicability of TTI for quality-controlled logistics in the frozen vegetable chains with the objective to maximize the product quality at the consumer end. The results show that TTI provided a more reliable quality indication compared to the actual traditional quality measurement Giannakourou and Taoukis (2003) also developed a Monte Carlo simulation model to explore the potential of the Least Shelf-life First Out (LSFO) system based on TTI. They concluded that the TTI-based LSFO can improve the consistency (uniformity) and quality of the products and minimize product rejection, and thus waste, at the consumer end. Dada and Thiesse (2008) investigated the effects of TTI-based product-issuing policies on product quality using simulation models. It is shown that the policies with automatically collected expiry dates and product quality can potentially improve the average final quality of items and reduce quality variations. Shih and Wang (2016) proposed a TTI-based cold-chain system where wireless sensors were used to collect temperature data and Critical Control Point (CCP) criteria were implemented throughout the entire delivery process. The experimental results proved that the proposed framework can bring benefits in terms of increased sales, extended distribution channels and reduced energy consumption. Beyond the studies which put the time-temperature sensors into focus, there is also research that looked into other sensor types. Abad et al. (2009) validated a smart RFID tag, with light, temperature, and humidity sensors integrated, to monitor and trace the fresh fish products in cold chains through laboratory and field tests. It was proven that the new smart-tag system has clear advantages over the conventional traceability tools in terms of more memory, reusability, no human participation, more resistance to humidity and environmental conditions, etc. Ruiz-Garcia et al. (2008) researched wireless sensor technology including humidity sensing for fruit storage and transport conditions. Their 
research contributed to the analysis of battery life under cooling conditions and the evaluation of the reliability of communications and measurements. Draganić et al. (2017) looked into a new type of compressive (compact) sensor that can describe the changes within the cold supply chain of $\mathrm{CO} 2$ level inside the packaging of table grapes. The proposed method was claimed to be able to prevent communication system overloading but still maintain high-quality monitoring. Sklorz et al. (2012) introduced a new sensor device for ethylene detection in fruit logistics applications. The measurement results showed an increased performance by factor 16 with respect to the ethylene related chromatographic peak maximum, which improves the sensor sensitivity to ethylene changes and enhances the accuracy of the prediction as a result.

Some studies analyzed the application of quality sensors in quality-controlled logistics in an abstract manner without focusing on a specific type of sensors in use. Bogataj et al. (2017) proposed to adopt the extended material requirements planning (EMRP) to dynamically adjust the plan based on the realtime recalculation of expected product shelf life to allow a better decision making based on the firstexpired-first-out (FEFO) policy. This paper demonstrates that a coupled cyber-physical ${ }^{2}$ system can bring in benefits by real-time decision-making empowered by IoT infrastructure such as automatic rerouting in postharvest logistics. The importance of supervising quality changes with ubiquitous sensors was addressed by Jedermann and Lang (2008) who claimed that the barriers to quality sensor implementation are not only costs but mainly energy consumption. In this sense, temperature and humidity sensors have advantages because they consume the least energy and measurements only need to be taken in intervals of several minutes (Jedermann and Lang, 2008). Haass et al. (2015) developed a simulation model to study the impact of IoT-based autonomous logistics on the bananas supply chain where intelligent containers can make their own decisions based on product quality conditions to enable quality-controlled distribution. It is shown that those intelligent containers can reduce food losses and carbon emissions in the banana supply chain and are therefore a promising option for trading companies to improve the operational efficiency and sustainability of their businesses. Heising et al. (2017) researched using intelligent packaging with quality-sensor embedded to enable quality-controlled logistics. Through combining a conceptual approach with simulation studies, they demonstrated that with intelligent packaging, quality-controlled logistics can lead to significant food waste reduction which will be further envisaged when dynamic pricing rested on predicted expiry dates is implemented.

\subsection{Quality-decay modeling}

In order to enable quality controlled logistics, quality sensors should be combined with quality-decay models that can effectively translate the sensor-collected data into quality metrics and ultimately the remaining shelf life of the products. Therefore, it is as important to have good quality-decay models as good sensors for ensuring quality-controlled logistics.

Time and temperature are commonly the most important causes of quality decay (senescence), and therefore time-temperature dependent models represent the mostly applied quality-decay modeling approach. A typical model is a logistic curve with time and temperature as independent variables (Tijskens and Polderdijk, 1996; Tromp et al., 2016; Tromp et al., 2017; Tromp et al., 2012). It is stated by Tijskens and Polderdijk (1996) that the logistic kinetics/behavior is frequently encountered in natural processes (e.g., France and Thornley, 1984; Thornley, 1976; Tijskens and Evelo, 1994); therefore it can be considered to have a biological foundation. The drawbacks of the classical logistic-curve model are that it does not take into account factors (e.g., humidity, ethylene) other than time and temperature, and that it has difficulty capturing the within-batch biological variations when making quality decay predications. The logistic regression model is able to include more variables than only time and temperature into the regression function and considers the withinbatch product variety (Lammertyn et al., 2000). This model is also more flexible because it is

${ }^{2}$ Cyber-Physical Systems (CPS) are integrations of computation, networking, and physical processes. Embedded computers and networks monitor and control the physical processes, with feedback loops where physical processes affect computations and vice versa 
independent of any biological assumption. However, compared to the classical logistic-curve model, the logistic-regression model lacks the biological foundation and is computationally more complex. The high computational burden could be a problem because in real-time monitoring which constantly combines newly available data for quality prediction updates, high computational speed is a crucial requirement.

Both the logistic-curve and logistic-regression models are so-call parametric models in which all the parameters of interest are in the finite-dimensional parameter spaces. With the development of big data technologies, new non-parametric machine-learning models with higher degrees of freedom, for example, Bayesian Network (e.g., Zhang et al., 2020) and Neural Networks (Chen et al., 2001; Singh et al., 2009; Soltani et al., 2015; Wang et al., 2017) are thriving in the domain of food quality prediction. However, the big data models have not yet been able to replace the traditional parametric quality-decay models governed by pre-specified mathematical functions due to the reasons such as intensive data requirement, and longer computational time. This implies that the traditional models still have their values to be retained.

\subsection{Knowledge gap}

Based on the literature review, we have observed the knowledge gap as follows. Firstly, most of the existing studies addressed the technical issues of quality sensor and decay model applications in the context of quality-controlled logistics. The "economic viability" of such applications which is the prerequisite for practical implementation was understudied, which may be a critical reason for the slow adoption of this new technology. This resulted in a lot of simulation-based feasibility studies but hardly any successful business case has been studied. Secondly, there lacks a comprehensive conceptual framework that can support the entire procedure for implementing the sensor-based quality-controlled logistics with quality-decay models; existing research often stresses part of the implementation issues on an ad hoc basis, lacking a comprehensive conceptual guideline. Thirdly, no efforts were made in distinguishing the levels (strategic vs operational) of values that the sensor-based quality-controlled logistics can add to the current fresh product businesses. Finally, there was, to our best knowledge, no research that explicitly studies the relationship between the quality variation of the products and the quality-sensor applications as well as the consequential impacts on logistic decisions.

In response to the identified knowledge gap, in this paper, we developed a comprehensive conceptual framework to analyze the cost-benefits of sensor-based quality-controlled logistics enabled by realtime adjustable quality decay models. The conceptual framework facilitates the evaluation of the costs and benefits for quality-sensor applications both at an operational level (i.e. logistic operations) and at a strategic level (i.e. distribution network design). Issues concerning standards, trust, and resilience of the digitalized supply chain are also part of the conceptual framework to be discussed. 


\section{Method}

Jabareen (2009), a highly cited work for conceptual framework development, declares that conceptual frameworks can be developed and constructed through a process of qualitative analysis. Jabareen defines a conceptual framework as a "plane" of linked concepts that together provide a comprehensive understanding of a phenomenon or phenomena. It is consistent with the definition from Miles and Huberman (1994) that a conceptual framework "layout the key factors, constructs or variables, and presumes relationships among them". Based on this principle, Jabareen (2009) proposed a new qualitative method for building conceptual frameworks composed of 8 phases. This research adopted that method to develop the proposed conceptual framework following the guideline below.

Phase 1: Mapping the selected data sources

It is related to map the spectrum of multidisciplinary literature regarding the phenomenon in question. In this research, we have conducted an extensive literature review on quality-sensor technology, quality decay models, and quality-controlled logistics which are the key components of the "phenomenon" i.e., sensor-based quality-controlled logistics enabling.

Phase 2: Extensive reading and categorizing of the selected data

The aim of phase 2 is to carefully read the collected literature and categorize them by discipline and scale of importance. In this research, after gathering the most relevant papers in phase 1 , we did an in-depth reading and categorize the data by the domains, i.e. quality sensors, quality decay models as well as their interface with the quality controlled logistics.

Phase 3: Identifying and naming concepts

With the observations in phase 2, the knowledge gap was identified, which provided the opportunities to come up with and name the new concepts, namely the "sensor-based quality-controlled logistic operations" and "sensor-based quality-controlled distribution network design".

Phase 4: Deconstructing and categorizing the concepts

The newly defined concepts were broken down again into the attributes including "quality sensor application", "information integration platform", "quality-decay modeling", "logistic operations", "distribution network design", etc.

Phase 5: Integrating concepts

In this phase, the deconstructed concepts are integrated again by scheme establishment (i.e. the graph for the generic procedure) and logical reasoning (the analysis on quality-controlled distribution network design as well as the elaboration on standards, trust, and resilience).

Phase 6: Synthesis, resynthesis, and making it all make sense

The storyline was synthesized and refined for several rounds to make the conceptual framework more and more sensible to ourselves.

Phase 7: Validating the conceptual framework

The aim of this phase to let other scholars or experts judge whether or not the conceptual framework makes sense to them. To realize that, we have consulted researchers and domain experts and presented the framework on many different occasions to get feedbacks.

Phase 8: Rethinking the conceptual framework 
A theory or a theoretical framework representing a multidisciplinary phenomenon that is dynamic and needs to be revised according to new insights, comments, literature, and so on. Jabareen (2009) points out that the advantages of conceptual framework analysis are its flexibility, its capacity for modification, and its emphasis on understanding instead of prediction. Therefore, in this research, we keep the description of the framework generic and open to leave room for further updates. 


\section{$4 \quad$ Conceptual framework}

The conceptual framework developed in this research is to serve as a guideline in practice for applying the connected quality-sensors (IoT) in quality controlled logistics. Since our focus here is on quality sensors, the framework implicitly presumes that a decent IoT infrastructure with traditional logistics sensors (e.g. location sensors) has been in place. On top of that, the added values of the quality sensors are to be investigated, which distinguishes our study from existing research in the literature. This conceptual framework consists of three parts: a generic procedure for implementing the sensorbased quality-controlled logistic operations (4.1), the accumulated data for quality-controlled distribution network design (4.2) as well as the associated issues of standard-setting, trust, and resilience (4.3).

\subsection{Logistic operations}

The sensor-based quality-controlled logistics can lead to an improvement in daily logistics operations along the F\&V supply chain. It requires the design of a generic procedure (Figure 1 ) that covers relevant aspects of the successful implementation of the new concept. This procedure is explained in the next sections.

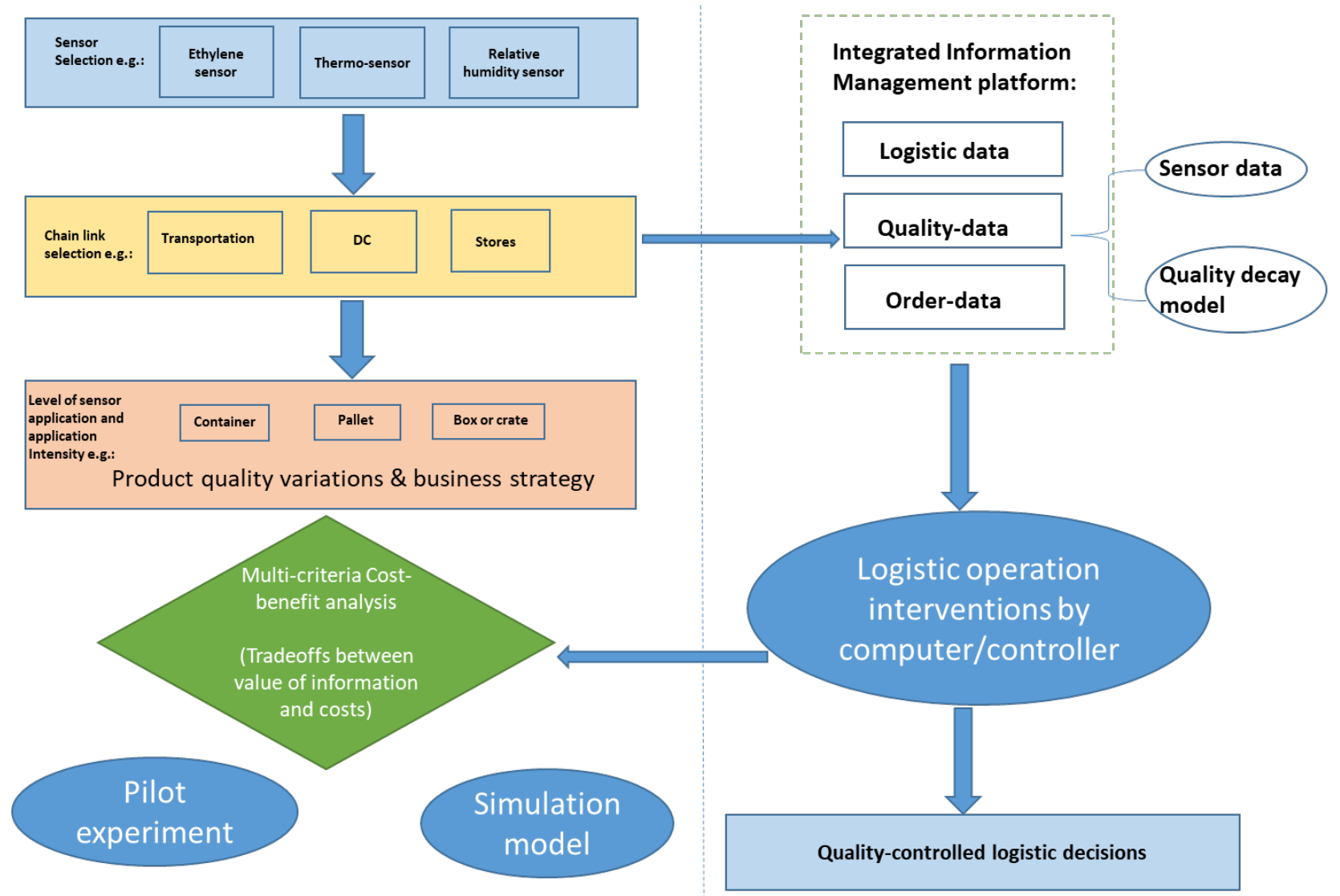

Figure 1. The generic procedure for implementing the sensor-based quality-controlled logistics operations

\subsubsection{Three-level selections}

The procedure starts with the ex-ante evaluation of a specific sensor-based quality-controlled logistic operation scenario in the F\&V supply chain. Such a scenario is constructed of a series of important selections at multiple levels. The first selection is concerning the choice of appropriate quality sensors. 
Trade-offs need to be weighed between the merit of certain quality information and the associated costs. For example, the thermo-sensors are the most commonly used quality sensors in practice because of the low price and temperature is the key factor for quality decay. The relative humidity sensor is also widely applied due to the low costs. However, such sensors can not provide information on, for instance, the concentration of ethylene which is highly correlated to the ripening process of some F\&V products. To obtain direct information on product ripening, ethylene sensors may be considered as an add-up to the thermo-sensors but the associated costs will be also higher. Hence, the value of additional ethylene information needs to be carefully justified against the extra sensor costs.

After selecting the suitable types of quality sensors, the locations for sensor applications in the supply chain are to be decided. The quality sensors can be installed in a fixed chain link, e.g., in the cold storage of a distribution center (DC) while they can also travel with the products through the entire supply chain as mobile data loggers (Verdouw et al., 2013). According to Verdouw et al. (2013), in Dutch floriculture, a sector regarded quite progressive in terms of supply chain digitalization, the most widely applied quality sensors are still the fixed sensors and data loggers (mobile sensors) without real-time communication capacity. The fixed sensors sticking to a fixed location can only measure the "environmental parameters" instead of the "product parameters", which may result in big measurement errors. For example, the "environmental temperature" in a reefer container can significantly deviate from the "product temperature" and brings about misleading information to the decision-makers. The mobile sensors without real-time communication capacity are mostly used in a defensive manner to identify the root causes of quality decay after the shipments have been accomplished (Scheer et al., 2011). Such sensors have the advantage of low costs compared to realtime mobile sensors but they fail to empower on-time operational decisions in the supply chain. Therefore, trade-offs must be analyzed between the benefits from real-time quality-based decision making and the required investments to realize it. Moreover, the chain-link selection for sensor applications also depends on the purpose or strategy of the involved companies. For example, if a retailer has the strategy on quality maximization to serve the high-end consumers, they should consider putting enough quality sensors on the shelves of the stores to closely monitor the quality of perishable products. By contrast, if the strategy is to offer competitive prices to the consumers, then it may be only necessary to apply a limited number of sensors to the bulk products in the stock room. Besides the location selection, the level at which the quality sensors should be implemented as well as the intensity of the implementation must be determined. There are multiple levels of units that the quality sensors can be applied to, normally including containers, pallets, boxes/crates, or even individual products. The selected unit level and sensor application intensity ${ }^{3}$ have direct impacts on the costs and performance of supply chain operations. Choosing a lower level of application units means more detailed information can be collected but it also means higher sensor costs may be incurred because more sensors are likely needed. For a selected unit level, higher application intensity (e.g., 10 sensors versus 1 sensor in one pallet) reduces the measurement errors, increases the statistical reliability of the collected information, but at the same time also brings up the sensor costs. Again, decisions must be made based on cost-benefit analysis where the within-unit and between-unit variations play a big role. The within-unit variations refer to the product-quality deviations for the products in the same sensor-application unit (e.g., within a pallet) and the between-unit variations refer to the product-quality deviations between sensor application units (e.g., between pallets). Both of them raise significant difficulties in monitoring and controlling the quality of products. In the current practice, many traders try to load homogenous cargos into the same batch to reduce the necessity for including quality decay into the decision making process. However, this is not always easy to realize because of the diversified product sourcing places and the volatile postharvest environmental conditions. If the within-unit product variations are high (e.g., when the products in one pallet are from an unprofessional smallholder farm), to get accurate estimates of the representative product quality, more sensors are required to be put into the unit. If the between-unit product variations are high (e.g., when the products in different pallets are from the farms with different professional levels), it may require every individual unit to be sensed separately with known initial quality.

\footnotetext{
${ }^{3}$ The amount of sensors applied to one measurement unit (e.g. container, crate/box)
} 


\subsubsection{Cost-benefit analysis}

As mentioned in the previous section, the selections on sensors, chain locations, application level, and intensities have pros and cons which need to be investigated in-depth by cost-benefit analysis. Generally speaking, the objective of the cost-benefit analysis is to balance the trade-offs between the added-value of sensor-collected data and the costs for sensor implementations. The ideal way to evaluate the costs and benefits of a specific supply chain scenario is to observe it directly in a real business setting that represents the real-life situation. However, the real-business scale implementation for an unproven concept could be very risky and costly. Therefore, the ex-ante evaluation with pilot experiments and computer simulations is proposed. The pilot experiments are conducted for proof of concept purpose. For example, the companies can put the quality sensors in several containers to continuously monitor the quality changes of the products as the basis to make data-driven logistic decisions. Such pilot experiments can bring about valuable insights on the costbenefit tradeoffs for quality sensor applications on a small scale but have the difficulty in generalizing the small-scale findings to the large-scale real-business settings. To enable results scaling up, computer simulations, a powerful tool for supply chain analysis (Schunk and Plott, 2000), can be adopted. The knowledge derived from the pilot study (e.g., relationships between different parameters) can be used as the inputs of the simulation models to mimic the supply chain operations on a realistic business scale. The pilot experiment can also be used to validate the simulation model, which is the other way around.

Moreover, the costs and benefits should not be regarded only from an economic perspective. Social and environmental aspects such as employment opportunity, energy use, greenhouse gas (GHG) emissions should also be taken into account. It is necessary to realize that the social and environmental goals are often contradictory to the economic incentives. For instance, digitalizing the logistic operations with quality sensors can undermine the manual job opportunities (e.g. manual quality control); applying large numbers of sensors in the supply chain will increase the energy use so as for GHG emissions. However, sometimes, social, economic, and environmental objectives can go hand in hand with each other as well. A digitalized supply chain may create more IT-related jobs; optimally arranging the goods flows through quality-controlled logistics can reduce food losses which are a significant contributor to global GHG emissions. Therefore, the simulation model must enable a multi-criteria analysis to evaluate the costs and benefits from different dimensions with an integrated viewpoint.

\subsubsection{Implementation scheme}

The ex-ante cost-benefit analysis lays down the foundation for the real implementation of sensorbased quality controlled logistics. The key to realizing that is to obtain an integrated information management platform (see Figure 1) that can consolidate order data, logistic data, and quality data from different companies throughout the supply chain in a real-time fashion. The order data includes information on the locations of the customers, product specifications, product dimensions, product prices, etc. The logistics data specify the features of shipments and warehousing activities such as transport modality, transport conditions, locations of the vehicle, size of the vehicles, the space and inventory of the DCs, the speed of product handling in the DCs, etc. Seamlessly connecting the logistic data to the order data can enable the identification of opportunities to improve logistic operations in the F\&V supply chains even without incorporating quality-related aspects. For example, companies can consolidate orders from different customers located in nearby places into one shipment to improve the loading factor and reduce per-unit transportation costs. By taking into account the real-time quality data collected by quality sensors, the room for logistic operation improvement becomes even larger. For instance, companies can remotely modify the conditions of the reefer containers such as changing the temperature according to the quality situation of the products at the very moment. They can also apply quality-based issuing policies like First-Expire-First-Out (FEFO) to maximize the product quality for their customers. With the real-time quality information, it is also possible to redirect good flows of low quality to the low-end market to minimize the economic losses. 
The sensor-collected data is usually not directly interpretable by the decision-makers to make informed decisions. The raw data, such as the temperature history of the product, must be translated by e.g. a quality-decay model to more tangible quality indicators like the remaining product shelf life. There are different kinds of quality decay models available to conduct quality predictions ranging from the classical time-temperature logistic curve models to the machine learning models with big data approaches. The type of model to be chosen depends on factors such as the selected sensor type, the model calculation speed, the level of decision units. For example, if only the thermo-sensors are applied, then the classical time-temperature logistic curve model can be used because it has a better biological foundation and less computational complexity (i.e. high computational speed) compared to logistic regression and machine learning models. On the contrary, if the sensed parameters are more than time and temperature, the logistic regression and machine learning models can be considered, however, at the costs of computational speed. No matter what type of model is used, it must allow an automatic and reliable real-time recalculation of the quality indicators to utilize the newly collected information. We refer to such models as dynamic quality decay models. They are different from the traditional static models where the input parameters have been already fixed before the start of logistic activities; consequentially, the model is unable to incorporate the new information during the activities to update the predictions. For the dynamic quality decay modeling, the timespan between two consecutive recalculation points needs to be carefully determined. If the timespan is set too long, the model will not be updated in time and create problems for on-time decision making. However, if the timespan is set too short, it will increase the computational burdens for the model which can result in more energy uses and heavier computational power requirements for speeding up. Therefore, selecting a model of low computational complexity would be beneficial when one wants to more frequently update the quality-decay model during logistic operations. Moreover, the more decision units that the company wants to monitor, the more computational power is required and the more energy will be consumed. This is because the model needs to recalculate the quality indicators for every decision unit after each predefined timespan. One way to reduce the computational burden is to combine the periodic review on input parameters with the advent-based model recalculations. Namely, the model reviews the newly available input parameter values after each predefined timespan and the recalculation is only triggered when significant changes in the input parameter values occur. After deriving the reliable quality information from the sensor data, to optimize the logistic activities accordingly, logistic operation interventions must be done by the dedicated human controllers or computers. For the human-controller scenario, the controllers will change the logistic conditions (e.g., temperature modification) or reorganize the logistic activities (goods flow redirection) based on their own knowledge together with the results from the quality decay model. Although the controllers can also be supported by the logistic optimization model that provides calculated logistic solutions, the final decisions will be made by the controllers. On the opposite, in the context of advanced IoT, complex pro-active behaviors are performed by computers, and no human operation is needed anymore. The interventions are purely governed by computer algorithms. This scenario sounds still like a utopia for the moment given the preliminary phase of sensor-based quality-controlled logistics but with the development of information technology and artificial intelligence, it may become reality faster than we think. No matter if actions are taken by humans or computers, the thresholds for triggering the interventions must be optimally settled. It should be avoided to set too high or too low thresholds for actions. If the threshold for alarming a disrupted event is too low (e.g., the predicted shelf life decreasing by one hour), there could be numerous alarms raised during the logistic process leading to unrealistic numbers of intervention requirements. By contrast, if the threshold is too high (e.g., the predicted shelf life decreasing by 5 days), it will prevent the alarming from notable quality disruptions. Again, the selected thresholds are also dependent on business strategies. In general, the threshold should be set higher for a cost-control strategy than that for a quality-maximization strategy. This is because logistic interventions are also costly. The benefits from the quality-informed decisions must exceed the costs for interventions.

Finally, the implementation phase is not separated from the phase of cost-benefit analysis. The whole procedure is a dynamic learning process. The knowledge learned from real implementations can serve as the new inputs for the simulation model to test more close-to-reality scenarios and explore more opportunities in quality-controlled logistic operations. 


\subsection{Distribution network design}

With the implementation of quality-controlled logistic operations, huge amounts of data will be accumulated. Those data are very valuable resources that provide the basis for the quality-controlled distribution network design. While quality-controlled logistic operations exploit the short-term opportunities to improve efficiency in daily F\&V chain management, the quality-controlled distribution network design helps the company to gain strategic advantages in the medium and long term. No matter whether a company manages its own supply chain or outsources the services to third-party logistics (3PLs), it should always evaluate the supply chain costs to discover the spots of inefficiency in the current supply chain network at least on a yearly basis. Such a mid-term evaluation usually does not lead to the change of the basic network structure (i.e. not changing the DC locations and capacities, not changing the sourcing regions and markets) but it does contribute to improved operational efficiency by, for instance, redirecting the aggregated goods flows of the referred period (e.g., one year) through the current network or changing shipment modality and routings. In addition to the yearly-based evaluation, the company also needs to conduct a strategic network evaluation for the long term. The strategic network evaluation aims to derive optimal supply chain settings by changing the basic structure of the supply chain (e.g., building new DCs, changing major suppliers, and markets). It is usually performed in a longer time frame (e.g., every 5 years), taking into account the long term business growth prospects. It can also be triggered by merger and acquisition activities, especially when distribution network overlaps exist between the merged companies. In the strategic network evaluation, besides operational costs, investment costs are also involved, and therefore returns on investment (ROI) needs to be taken into account.

Different from non-perishable products, the quality aspect of fresh products has substantial impacts on the optimal configuration of the distribution network. However, due to the lack of reliable quality data, in practice, the quality aspect is often not adequately considered during the network design process. This will lead to increased supply chain costs, decreased average product quality, and, thus, increased product losses. By valorizing the accumulated sensor data with the help of quality decay models, companies can better understand the quality-decay process through the supply chain and improve the mid-and long-term performance accordingly. In the mid-term, knowing the average shelf life of the products can help the company to determine the proper transport modalities and conditions, finetune the storage conditions, refine the vehicle routings, etc. In the long term, based on the weighted average shelf life of the good flows in each shipment lane (an origin-destination combination) of a reference period, the company can determine the optimal location of a DC that maximizes the average remaining shelf life of the products on the market. Furthermore, based on the shelf life information, the company can calculate the appropriate stock levels of the DCs to reduce product losses but still maintain a good service level. The knowledge of product quality can also help companies select the most appropriate suppliers who supply the right quality to the right market.

\subsection{Standards, trust, and resilience}

The current lack of standards in terms of data interoperability is a barrier for quality-controlled logistics to integrate different systems, e.g., logistic systems, enterprise management systems in the context of IoT (Verdouw et al., 2011). It is especially true when it comes to the quality standards in the perishable product supply chains. Different from the Dutch floriculture sector that has mature databases of high-quality product reference information (Verdouw et al., 2013), the F\&V products are relatively unstandardized. For many F\&V products, there are no uniformly accepted and quantifiable quality standards. This creates difficulties in the communication of product quality between companies in the supply chains. From the quality decay modeling point of view, lack of standards makes the prediction of the quality parameters and remaining shelf life difficult and arbitrary. Therefore, to successfully implement the sensor-based quality-controlled logistics, establishing quality standards for F\&V products are a priority.

Trust between different companies and chain players is the key to ensure efficient supply chain coordination which is essential for successful quality-controlled logistics implementation. Data privacy, 
especially for the product-quality data, is a critical issue to protect the competitive advantage of a company in F\&V supply chains. It is, therefore, important to design a rigorous data-sharing mechanism to let different data users only access the data they are supposed to know at an appropriate level (e.g. aggregated versus detailed, complete versus partial). Efficient supply chain coordination also requires fair distributions of benefits from data-sharing, which again relies on the trust between companies. The leading chain player (e.g., an independent institute or an open system operator) should take the responsibility to ensure a fair rewarding scheme for data sharing to be implemented.

The resilience of the F\&V chain under the sensor-based quality-controlled logistics is another issue worth being investigated. Supply chain resilience refers to the ability of a supply chain to recover from an unexpected disruption to its original situation (Barroso et al., 2015; Ribeiro and Barbosa-Povoa, 2018). The sources of traditional food supply chain disruptions range from crop yields reduction due to disastrous weather, to supply or market standstills due to disease outbreaks (e.g. coronavirus outbreaks), to infrastructure failure (e.g. power failure for refrigerated distribution centers), and so on. Compared to the traditional food supply chain, the digitalized supply chain powered by sensor technology has both advantages and disadvantages with regard to resilience. The digitalized supply chain requires less human workforce to be involved in daily operations. This is especially beneficial for business continuation during the period when hazards like coronavirus occur. However, heavy digitalization can also bring in risks to the supply chain. For example, when a crucial system error is occurring, e.g., either due to the errors of the quality-decay models or software failure or even cyberattacks, the consequences on the business will also be significant. If human control is no longer available, it may result in huge chaos and cause substantial losses to the companies. Therefore, even though in theory IoT technology can enable highly automated logistic operations, it is still proposed that certain degrees of human interventions are retained to improve the resilience of the digitized supply chain. Moreover, although it is required to have a centralized information management platform to consolidate data (as discussed in subsection 3.1.3), smart architecture solutions should be searched to enable the decentralized function realization (e.g., embed the quality-decay model into sensors and do the calculation locally). This can mitigate the risks of the central platform collapse and improve supply chain resilience. 


\section{Discussion}

In this research, we developed a conceptual framework to analyze the implementation of sensorbased quality-controlled logistics in the context of IoT. It distinguished two levels of added values for sensor applications, i.e., the level of logistic operations and the strategic level of distribution network design. A generic procedure was proposed to guide the analysis of the quality-controlled logistic operations in day-to-day businesses. Then, the added values of the accumulated sensor data for quality-controlled distribution network design were also discussed. Furthermore, other relevant issues including standard establishment, trust enhancement, and resilience improvement in the F\&V chains were also addressed.

Finally, this conceptual paper is one deliverable of WP 1 of the large project. It aims to provide a guideline to develop the pilot for proof of concept in WP5 and ultimately make impacts in practice. . Therefore, following the conceptual framework, we will develop an evaluation framework to access the proof of concept on operational, tactical, and strategic levels. It provides the basis for the follow-up researches on the sensor-based quality-controlled logistics in the mango supply chain from Senegal to the Netherlands and also other supply chains. In this sense, this framework does not only fill the scientific knowledge gap in the literature but can also help the practitioners to tackle the practical problems in the phase of implementation.

Future research should focus on applying the framework in more case studies, especially addressing the conflicting effects of the new approach from different perspectives other than economic consideration. Taking into account the social and environmental aspects makes the problem much more complex. For example, how many losses of FTEs of employment opportunities make up for reduced product loss and emissions is a difficult question to answer. It, therefore, requires more effort to be put into making the impacts in different dimensions comparable to each other. Moreover, improved sensing and prediction capabilities can also lead to a more homogenous quality of storage and shipments in the upstream supply chain activities. For example, computer vision, quality verification, and shelf-life prediction can help to directly bundle similar products after the harvest. This could also feed into quality-controlled logistics concepts because it can improve the overall monitoring quality throughout the postharvest chain due to the enhanced knowledge of the initial quality of the products. As a result, research on quantifying the added values of sensor-based quality-controlled logistics in the first miles should be carried out. 


\section{Literature}

Abad, E., Palacio, F., Nuin, M., Zárate, A.G.d., Juarros, A., Gómez, J.M., Marco, S., 2009. RFID smart tag for traceability and cold chain monitoring of foods: Demonstration in an intercontinental fresh fish logistic chain. Journal of Food Engineering 93(4), 394-399.

Barroso, A., Machado, V., Carvalho, H., Machado, V.C., 2015. Quantifying the supply chain resilience. Applications of contemporary management approaches in supply chains, 13-32.

Ben-Daya, M., Hassini, E., Bahroun, Z., 2019. Internet of things and supply chain management: a literature review. International Journal of Production Research 57(15-16), 4719-4742.

Bogataj, D., Bogataj, M., Hudoklin, D., 2017. Mitigating risks of perishable products in the cyberphysical systems based on the extended MRP model. International Journal of Production Economics 193, 51-62.

Chen, C., Ramaswamy, H., Alli, I., 2001. Prediction of quality changes during osmo-convective drying of blueberries using neural network models for process optimization. Drying Technology 19(3-4), 507523.

Dada, A., Thiesse, F., 2008. Sensor applications in the supply chain: the example of quality-based issuing of perishables, The Internet of Things. Springer, pp. 140-154.

de Keizer, M., Akkerman, R., Grunow, M., Bloemhof, J.M., Haijema, R., van der Vorst, J.G.A.J., 2017. Logistics network design for perishable products with heterogeneous quality decay. European Journal of Operational Research 262(2), 535-549.

Draganić, A., Orović, I., Stanković, S., Zhang, X., Wang, X., 2017. Compressive sensing approach in the table grape cold chain logistics, 2017 6th Mediterranean Conference on Embedded Computing (MECO). IEEE, pp. 1-4.

France, J., Thornley, J.H., 1984. Mathematical models in agriculture. Butterworths.

Giannakourou, M., Taoukis, P., 2003. Application of a TTI - based distribution management system for quality optimization of frozen vegetables at the consumer end. Journal of food science 68(1), 201-209. Guo, X., Broeze, J., Groot, J., Axmann, H., Vollebregt, M., 2019. A global hotspot analysis on food loss \& waste and associated greenhouse gas emissions. CCAFS Working Paper no. 290. Wageningen, the Netherlands: CGIAR Research Program on Climate Change, Agriculture and Food Security (CCAFS). Haass, R., Dittmer, P., Veigt, M., Lütjen, M., 2015. Reducing food losses and carbon emission by using autonomous control-A simulation study of the intelligent container. International Journal of Production Economics 164, 400-408.

Heising, J.K., Claassen, G., Dekker, M., 2017. Options for reducing food waste by quality-controlled logistics using intelligent packaging along the supply chain. Food Additives \& Contaminants: Part A 34(10), 1672-1680.

Hribernik, K.A., Warden, T., Thoben, K.-D., Herzog, O., 2010. An internet of things for transport logistics-an approach to connecting the information and material flows in autonomous cooperating logistics processes, Proceedings of the 12th international MITIP conference on information technology \& innovation processes of the enterprises. pp. 54-67.

Jabareen, Y., 2009. Building a conceptual framework: philosophy, definitions, and procedure. International journal of qualitative methods $8(4), 49-62$.

Jedermann, R., Lang, W., 2008. The benefits of embedded intelligence-tasks and applications for ubiquitous computing in logistics, The internet of things. Springer, pp. 105-122.

Jedermann, R., Nicometo, M., Uysal, I., Lang, W., 2014. Reducing food losses by intelligent food logistics. The Royal Society Publishing.

Lacey, M., Lisachuk, H., Giannopoulos, A., Ogura, A., 2015. Shipping smarter: IoT opportunities in transport and logistics. Deloitte University Press.

Lammertyn, J., Aerts, M., Verlinden, B.E., Schotsmans, W., Nicolaı, B.M., 2000. Logistic regression analysis of factors influencing core breakdown in 'Conference'pears. Postharvest Biology and Technology 20(1), 25-37.

Miles, M.B., Huberman, A.M., 1994. Qualitative data analysis: An expanded sourcebook. sage. Minerva, R., Biru, A., Rotondi, D., 2015. Towards a definition of the Internet of Things (IoT). IEEE Internet Initiative, Torino, Italy.

Ribeiro, J.P., Barbosa-Povoa, A., 2018. Supply Chain Resilience: Definitions and quantitative modelling approaches-A literature review. Computers \& Industrial Engineering 115, 109-122. 
Ruiz-Garcia, L., Barreiro, P., Robla, J.I., 2008. Performance of ZigBee-Based wireless sensor nodes for real-time monitoring of fruit logistics. Journal of Food Engineering 87(3), 405-415.

Scheer, F., Snels, J., Beulens, A., 2011. Business Opportunities Tracking \& Tracing

Tuinbouwproducten. Tuinbouw Digitaal/Wageningen UR Food \& Biobased Research, 60p.

Shih, C.-W., Wang, C.-H., 2016. Integrating wireless sensor networks with statistical quality control to develop a cold chain system in food industries. Computer Standards \& Interfaces 45, 62-78.

Singh, R.R.B., Ruhil, A.P., Jain, D.K., Patel, A.A., Patil, G.R., 2009. Prediction of sensory quality of UHT milk - A comparison of kinetic and neural network approaches. Journal of Food Engineering 92(2), 146-151.

Sklorz, A., Janßen, S., Lang, W., 2012. Gas Chromatograph based on Packed $\mu$ GC-Columns and $\mu-$ Preconcentrator Devices for Ethylene Detection in Fruit Logistic Applications. Procedia Engineering 47, 486-489.

Smith, D., Sparks, L., 2004. Temperature controlled supply chains. Bourlakis, MA and PWH Weightman, Food Supply Chain Management, 179-198.

Soltani, M., Omid, M., Alimardani, R., 2015. Egg quality prediction using dielectric and visual properties based on artificial neural network. Food analytical methods 8(3), 710-717.

Sun, C., 2012. Application of RFID technology for logistics on internet of things. AASRI Procedia 1, 106-111.

Taoukis, P., Labuza, T., 2003. Time-temperature indicators (TTIs). Novel food packaging techniques, 103-126.

Thornley, J.H., 1976. Mathematical models in plant physiology. Academic Press (Inc.) London, Ltd. Tijskens, L., Evelo, R., 1994. Modelling colour of tomatoes during postharvest storage. Postharvest Biology and Technology 4(1-2), 85-98.

Tijskens, L.M.M., Polderdijk, J.J., 1996. A generic model for keeping quality of vegetable produce during storage and distribution. Agricultural Systems 51(4), 431-452.

Tromp, S.-O., Haijema, R., Rijgersberg, H., van der Vorst, J.G., 2016. A systematic approach to preventing chilled-food waste at the retail outlet. International Journal of Production Economics 182, 508-518.

Tromp, S.-O., Harkema, H., Hogeveen, E., Rijgersberg, H., Woltering, E.J., 2017. On the validation of improved quality-decay models of potted plants. Postharvest Biology and Technology 123, 119-127.

Tromp, S.-O., Rijgersberg, H., da Silva, F.P., Bartels, P., 2012. Retail benefits of dynamic expiry dates-Simulating opportunity losses due to product loss, discount policy and out of stock.

International Journal of Production Economics 139(1), 14-21.

Van Der Vorst, J.G., Tromp, S.-O., Zee, D.-J.v.d., 2009. Simulation modelling for food supply chain redesign; integrated decision making on product quality, sustainability and logistics. International Journal of Production Research 47(23), 6611-6631.

van der Vorst, J.G., Tromp, S., van der Zee, D.-J., 2005. A simulation environment for the redesign of food supply chain networks: modeling quality controlled logistics, Proceedings of the Winter Simulation Conference, 2005. IEEE, p. 10 pp.

van der Vorst, J.G., van Kooten, O., Luning, P.A., 2011. Towards a diagnostic instrument to identify improvement opportunities for quality controlled logistics in agrifood supply chain networks.

International journal on food system dynamics 2(1), 94-105.

van der Vorst, J.G., van Kooten, O., Marcelis, W., Luning, P., Beulens, A.J., 2007. Quality controlled logistics in food supply chain networks: integrated decision-making on quality and logistics to meet advanced customer demands.

Verdouw, C.N., Beulens, A., Van Der Vorst, J., 2013. Virtualisation of floricultural supply chains: A review from an Internet of Things perspective. Computers and electronics in agriculture 99, 160-175. Wang, J., Yue, H., Zhou, Z., 2017. An improved traceability system for food quality assurance and evaluation based on fuzzy classification and neural network. Food control 79, 363-370.

Wong, C.Y., McFarlane, D., Zaharudin, A.A., Agarwal, V., 2002. The intelligent product driven supply chain, Systems, Man and Cybernetics, 2002 IEEE International Conference On. IEEE, p. 6 pp. vol. 4. Zhang, H., Feng, H., Cui, Y., Wang, Y., 2020. A Fuzzy Bayesian Network Model for Quality Control in $\mathrm{O} 2 \mathrm{O}$ e-Commerce. International Journal of Computers, Communications \& Control 15(1). 



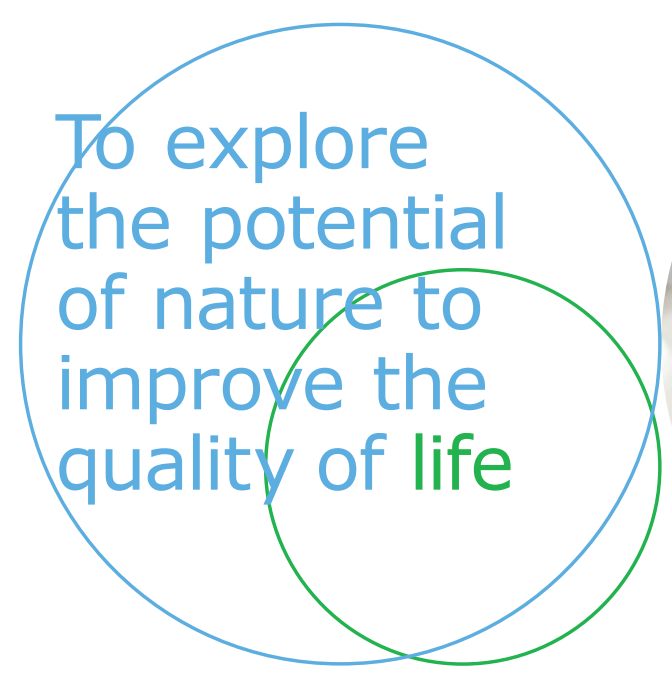

Wageningen Food \& Biobased Research Bornse Weilanden 9

6708 WG Wageningen

The Netherlands

www.wur.eu/wfbr

Einfo.wfbr@wur.nl

Report 2131

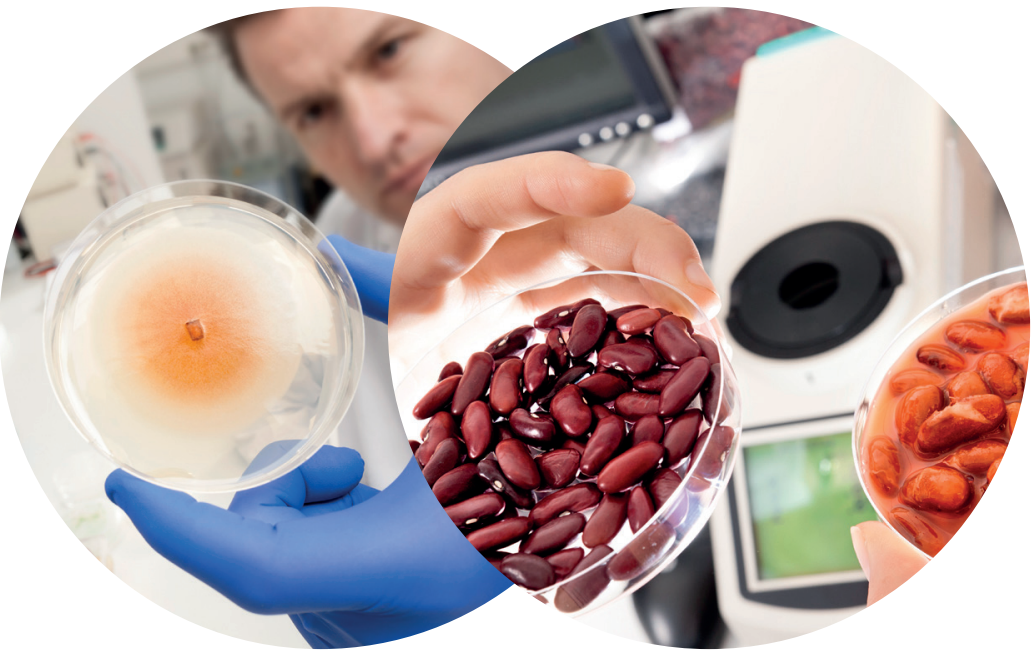

The mission of Wageningen University and Research is "To explore the potential of nature to improve the quality of life". Under the banner Wageningen University \& Research, Wageningen University and the specialised research institutes of the Wageningen Research Foundation have joined forces in contributing to finding solutions to important questions in the domain of healthy food and living environment. With its roughly 30 branches, 6,500 employees (5,500 fte) and 12,500 students, Wageningen University \& Research is one of the leading organisations in its domain. The unique Wageningen approach lies in its integrated approach to issues and the collaboration between different disciplines. 